\title{
Textos, tessituras e filamentos: as escritoras de si
}

A aventura de contar-se: feminismos, escrita de si e invenções da subjetividade.

RAGO, Margareth.

Campinas: Unicamp, 2013. 344 p.

Margareth Rago é uma escritora feminista e libertária que inspira estudantes de diferentes territórios e saberes. Na cartografia de suas narrativas, as memórias de mulheres apagadas da história dos "vencedores" figuram entre poéticas e políticas de resistência. Ela graduouse em História e Filosofia pela Universidade de São Paulo, cursou o mestrado e o doutorado em História, na Universidade Estadual de Campinas (UNICAMP). Trabalhou pelo mundo lecionando na Universidade Federal de Uberlândia, no Connecticut College, nos Estados Unidos, realizou seminários na Universidade de Paris 7 e foi professora visitante na Columbia University. Foi uma das criadoras e diretora do Arquivo Edgar Leuenroth da UNICAMP. 
Autora de diversos artigos, publicou livros que narram histórias, que rompem tradições e que alinhavam memórias. Entre as obras de destaque da autora, podemos citar "Do Cabaré ao lar. A utopia da cidade disciplinar. Brasil, 1890 1930" (Paz e Terra, 1985); "Entre a história e a liberdade: Luce Fabbri e o anarquismo contemporâneo" (UNESP, 2002), traduzido para o espanhol e para o italiano; "Feminismo e anarquismo no Brasil. Audácia de sonhar" (Achiamé, 2007); e "Mujeres libres da Espanha: documentos da revolução espanhola", com Maria Clara Biajoli (Achiamé, 2008). Cada novo livro da Margareth abre as portas e janelas para que as mulheres se libertem a cada dia, significando um sim à vida! Autora de fôlego, suas peripécias não param por aí. Coordena, junto com Tânia Navarro Swain e Marie-France Dépèche, a revista digital feminista internacional Labrys, estudos feministas (bilíngue português-francês) e coedita a Revista Aulas. Como professora e pesquisadora, é incansável. Ela propõe, como temas de ensino e pesquisa, teorias da história, feminismos, anarquismos, produção de subjtividade, arte e gênero, além de versar sobre as obras de Michel Foucault e Gilles Deleuze.

Na obra "A aventura de contar-se: feminismos, escrita de si e invenções da subjetividade", Margareth nos ensina sobre o processo de tessitura que é necessário para constituir, entender e analisar a história no mundo e no Brasil. Seu texto é poético e nos seduz a conhecer, em cada página dessa rede de relações e de tramas, as trajetórias de Amelinha, Criméia, Norma, Maria, Ivone, Gabriela e Tânia e a revisitar, no tecer das histórias sobre a Ditadura, os feminismos e as histórias de si:

'Como é que sabemos isso? Pelo próprio tecido'. Isso acontecia não só porque a tecelagem, tal como a escrita e outras artes visuais, fosse freqüentemente 'usada para marcar ou anunciar informação' e como 'meio mnemônico para registrar fatos e outros dados', mas também porque têxteis comunicam, de fato, em termos das imagens que aparecem no lado direito do pano, embora este seja apenas o sentido mais superficial em que processam e armazenam dados. $^{1}$

A escritora nos conta sobre as infâncias, as dificuldades, as vitórias, as lutas e as memórias de sete mulheres que constituíram marcas no feminismo brasileiro. As mulheres-personagens são plurais em seus movimentos e, ao mesmo tempo, tão singulares e marcantes como as lutas que se propõem. Constroem assim as "artes feministas da existência" e "[...] escapam às estratégias moleculares do poder, às sofisticadas tecnologias biopolíticas de produção da individualidade na 'sociedade de controle' [...]".2 O desenho da obra é composto de três partes: Experimentações, Cartografias e Um lugar no mapa. A geografia desse enredo é intensa e complexa e produz uma leitura do passado por meio de relatos orais e escritos compondo um espaço autobiográfico, que, segundo ela nos informa, é "[...] entendido a partir dos diferentes tipos de narrativas de si, entre memórias, depoimentos, entrevistas, correspondências, diários ou blogs, que permitem cartografar a própria subjetividade [...]". ${ }^{3}$

Não é só contar, o trabalho da autora é registrar as marcas discursivas que constituíram possibilidades de mudanças das subjetividades, de construções de si. Embasada pelos estudos sobre as "artes da existência" discutidas por Foucault, Margareth Rago mostra como os discursos das militantes estão relacionados às vivências e experiências, como elas registram, marcam, mudam as posturas e as subjetividades e redesenham seus caminhos políticos. As subjetividades riscam papel, telas, textos e oportunizam à autora contar os processos de subjetivação e os cuidados de si utilizados pelas contadoras de histórias sobre suas vidas. Afirma ela:

Educadas, entre os anos 1950 e 1960, para a virgindade, o casamento monogâmico indissolúvel, a maternidade e os cuidados com a família e para a passividade e o silêncio, abriram caminhos próprios, singulares [...]. Criticaram e desconstruíram os modos tradicionais de produção da subjetividade e propuseram outros. Contribuíram e contribuem decisivamente para a construção de um pensamento crítico. ${ }^{4}$

Rago trata de reinvenções, reestruturações, fugas subjetivas e espaços de constituição do eu. Ao abordar essas subjetividades, das vidas dessas mulheres, a autora delicadamente assume não só a postura de narradora, mas de guia na leitura para encontrarmos também traços nossos, fugas e reinvenções nossas de um eu que também busca nos feminismos modos de pensarse e agir no mundo.

Amélia e Criméia são irmãs. Viveram durante o período da Ditatura Militar em meio à resistência política. Filhas de um militante do $\mathrm{PCdoB}$, relatam histórias de dor, sofrimento e também, de luta e coragem. Ambas foram perseguidas, presas e torturadas pelos militares e "[...] trazem à tona essas experiências [...], necessitam encontrar outros caminhos subjetivos de expressão para garantir a sobrevivência psíquica diante do insuportável [...]". ${ }^{5}$ Visibilizaram 
suas dificuldades de atuação e suas necessidades de pensar em feminismos que agissem dentro do partido da esquerda. Descritas como cheias de vida, alegres e irônicas, visualizamos subjetividades que sobreviveram às torturas da Ditadura Militar e patriarcal e de outras opressões que suas memórias reorganizam e reinventam.

Diferente delas, Otília era uma das moças que fazia curso de Ciências Sociais na Faculdade de Ciências Humanas de São Paulo, mas que não gostou da chateação que estava e decidiu que queria outras experiências. Apaixonada pela personagem de Gabriela, cravo e canela, obra de autoria de Jorge Amado, a estudante, buscando-se, conta, em sua biografia, que encontrou "Gabriela escondida na pele de Otília" e foi viver como prostituta. Leitora de Foucault e de Guattari, Gabriela também mudou a vida de muitas prostitutas e, em parceria com Doroth, prostituta, e Flávio Lenz, jornalista, criou a ONG Davida. TrabaIharam com outras propostas de pensar e agir criaram o jornal Beijo da Rua, no qual Gabriela tem uma coluna em que expressa suas maneiras de ver o mundo, nas quais subjetiva e ensina diferentes formas de ser mulher.

Ivone fez de Deus uma entidade muito mais próxima das vivências de quem acredita em uma divindade. Abandonou dogmas religiosos para pensar em um feminismo que se aproximasse da Teologia, para, então, entender as mulheres que acreditam e se sustentam pela fé. Traz para a luta feminista o espaço da religião como um espaço político para contribuir com uma subjetividade que não se domestica, mas que resiste. Critica a separação entre religião e feminismos alegando a importância da atuação das mulheres para uma luta que desfaça o aspecto punitivo divino e ensine as mulheres a recriarem seus modos de ser e a pensarem as suas crenças de outros modos.

De espaços tão dogmáticos quanto os enfrentados por lvone, Maria refaz os caminhos entre o Marxismo e a Psicanálise, e, segundo Margareth Rago, busca um feminismo mais sensível. Em sua ałuação como professora e pesquisadora, Maria luta para entendermos as necessidades de os movimentos feministas repensarem suas perspectivas e práticas. Não só a tese de doutorado, mas toda a sua empreitada acadêmica é para uma feminização das relações e do mundo. As vivências e as experiências de Maria contam de resistência, de subjetivações políticas e de uma sensibilidade que refaça nossas compreensões, que desestabilize as verdades com simples dados sociais.
Norma, em sua poética de viajante, atenta aos detalhes e belezas do mundo e faz das artes e da literatura as tessituras das histórias. Da leitura de Bachelard, ela tira uma lição importante: a imaginação. Ela trata da sensibilidade e dos possíveis sentidos das leituras como perspectivas para um mundo possível com base nas escritas. Trata de si e do mundo sem separar dogmaticamente nenhuma das possibilidades de se perceber no mundo. Faz as ligações, alinhava as vivências e as práticas textuais sem fazer simplificações do que poderia ser sua subjetividade. Margareth nos mostra como os feminismos são possíveis, são passíveis das subjetividades, constroem-se como aprendemos com Norma e Bachelard, a partir da imaginação, e pontua: "Norma ousava navegar na contramão das ideologias correntes, em sua intensa busca de novas potências de existir, fora dos enquadramentos familiares, tanto quanto da rigidez da vida universitária ou dos grupos políticos revolucionários [...]". ${ }^{6}$

Tânia é apresentada por Margareth como pesquisadora feminista de renome e com grande atuação na academia, escritora que faz das leituras feministas e foucaultianas caminhos possíveis para recontar a História das mulheres apagadas do imaginário social. Tânia traça linhas possíveis entre os feminismos, as lutas lesbianas e as possibilidades de atuação política dentro da universidade. Registra seus estudos e, em suas atuações como professora universitária, os esforços por um feminismo que ultrapasse as barreiras impostas pelas instituições acadêmicas. Trata de perspectivas da subjetividade que invadem e corrompem as práticas acadêmicas, que as aproximem das comunidades e das vivências. Estudos que não falam sobre as mulheres, mas que falam por meio das mulheres, em suas vozes e suas práticas. Fez das viagens e dos lugares por onde passou uma cartografia que se traduz na escrita de si. Estudou na França e trabalhou no Canadá, de onde visualizamos sua influência teórica e ativista.

Margareth, com essas histórias de vida, compõe as escrituras de si e as subjetividades e subjetivações dessas feministas sem abandonar, em nenhum momento, o olhar que segue as linhas de seu livro. A todo o momento, somos interpeladas/os, somos chamadas/os a encontrar-nos nos excertos. Seu livro lembra uma aula, lembra uma contação de histórias e lembra-nos de nós mesmos/as. Embasada nas noções de escritas de si, Margareth se escreve e nos inscreve em suas tessituras discursivas. Ela apresenta, em seus enunciados, os desejos e as potencias feministas de não aceitar as naturalizações, faz da indignação um 
sopro de coragem, de muitas lutas e de liberdade.

Mais que o movimento de contar-se e de contar as histórias dessas feministas que mudaram os movimentos sociais brasileiros e internacionais, Margareth nos inspira. Faz-nos pensar em quais são as necessidades de nossos movimentos de hoje. Trata de feminismos que são riscos, rabiscos e texturas que estão em todos os cantos, que aparecem nas grandes capitais, nas cidades interioranas, nas salas de aula e nas redes sociais. Diríamos que o livro é uma "Marcha das Vadias". Lemos corpos, histórias, tristezas, indignações e muitas coisas para mudar. Comparamos à marcha não apenas por uma política que se faz ao caminhar, mas pelos barulhos e incômodos que causam.

Nossas ideias ficam inquietas, nossas subjetividades ficam às espreitas dessas vidas que passam linha após linha em nossa frente. Vamos ficando vermelhas/os, vamos nos sentindo incomodadas/ os e vamos nos olhando em cada cena, vamos pensando em nossas mãos e em nossos rostos. A aventura de contar-se, como destaca o prefácio de Márcio Seligmann-Silva, nos contagiou. Não há como terminar a obra com mãos trêmulas com a garganta seca e uma vontade inexplicável de escrever sobre si. Um livro que, mais que estímulo, nos faz pensar em nós mesmas/os e em como nós podemos repensar nossas vivências e subjetividades, um livro-vadia que nos ensina a entretecer, a alinhavar e a ter as vidas nas pontas dos dedos, nas palmas das mãos. Por um mundo mais filógino, ${ }^{7}$ ela reinventa o papel das mulheres na cultura:
A meu ver, em nossos tempos, [...] os feminismos, em suas dimensões, ultrapassam os limites instituídos entre público e privado, corpo e alma razão e emoção, essência e aparência, centro e periferia, fronteiras que as esquerdas infelizmente respeitaram. ${ }^{8}$

\section{Notas}

1 Sadie PLANT, 1999, p. 66, grifo da autora

${ }^{2}$ Margareth RAGO, 2013, p. 29.

${ }^{3}$ RAGO, 2013, p. 33

${ }^{4}$ RAGO, 2013, p. $35 .{ }^{5}$ RAGO, $2013, .73$.

${ }^{6}$ RAGO, 2013, p. 94.

${ }^{8}$ RAGO, 2013, p. 319-320.

${ }^{7}$ Margareth Rago escreveu um texło que propõe algumas reflexões sobre o lugar do feminino em nossa cultura questionando se as reações misóginas que a luta pela emancipação das mulheres tem provocado ao longo de sua história podem sugerir alternativas de construção de uma cultura filógina (RAGO, 2001).

\section{Referencias}

PLANT, Sadie. Mulher digital: o feminino e as novas tecnologias. Rio de Janeiro: Record; Rosa dos Tempos, 1999.

RAGO, Margareth. A aventura de contar-se: feminismos, escrita de si e invenções da subjetividade. Campinas: Unicamp, 2013. 344 p.

"Feminizar é preciso: por uma cultura filógina". São Paulo em Perspectiva: Revista da Fundação Seade, São Paulo, v. 15 n. 3, p. 5866, jul.-set. 2001.

Me. Samilo Takara Universidade Estadual de Maringá Dra. Patrícia Lessa Universidade Estadual de Maringá 